\title{
Gestalt Counseling Effectiveness with Engineering Techniques to Increase Self-Consideration in Learning Process
}

\author{
Efektifitas Konseling Gestalt dengan Teknik Berkeliling untuk Meningkatkan Percaya Diri \\ dalam Proses Pembelajaran
}

\author{
Arief Munandar ${ }^{1}$, Nyoman Dantes ${ }^{2}$, Wayan Tirka ${ }^{3}$ \\ ${ }^{123}$ Universitas Pendidikan Ganesha \\ e-mail: simunandar@gmail.com
}

Received January 05, 2017 Revised February 25, 2017

Accepted April 06, 2017

Published Online June 30, 2017

\section{Conflict of Interest}

Disclosures:

The authors declare that they have no significant competing financial, professional or personal interests that might have influenced the performance or presentation of the work described in this manuscript.

\begin{abstract}
Confidence is important to be possessed by students through the learning process, students who have low self-confidence will be less optimal in developing ability. This study aims to determine the effectiveness of gestalt counseling with the technique around to improve confidence in the learning process in students of class XI MIA 4 SMA Negeri 1 Singaraja academic year 2016/2017. This type of research is pre-experimental with one group pretestposttest design. Samples of research were six students selected through purposive sampling technique. Methods of data collection using a confident questionnaire that has been calculated the validity and reliability. The subjects from the study were students of class XI MIA 4 who had low self-esteem. Data analysis technique used is t-test statistical analysis technique. The results from the analysis, found that gestalt counseling with the technique of traveling can increase confidence. It is concluded from the analysis result, $t$ count> table with significance level $5 \%(4,38>2,015)$. The results from the analysis show that the hypothesis proposed in this study is acceptable. As the implication of this research is expected to be an alternative for counseling teachers in schools in improving student self-confidence.
\end{abstract}

Keywords: gestalt counseling, walking technique, confidence

Abstrak: Percaya diri penting dimiliki oleh siswa dalam proses pembelajaran, siswa yang memiliki percaya diri rendah akan kurang optimal dalam mengembangkan kemampuannya. Penelitian ini bertujuan untuk mengetahui efektifitas konseling Gestalt dengan teknik berkelilinguntuk meningkatkan percaya diri dalam proses pembelajaran pada siswakelas XIMIA 4 SMA Negeri 1 Singaraja tahun ajaran 2016/2017. Jenis penelitian ini adalah praeksperimental dengan rancangan one group pretest-posttest design. Sampel penelitian sebanyak 6 siswa yang dipilih melalui teknik purposive sampling. Metode pengumpulan data menggunakan angket percaya diri yang telah dihitung validitas dan reliabilitasnya. Subjek penelitian adalah siswa kelas XI MIA 4 yang memiliki percaya diri rendah. Teknik analisis data yang digunakan adalah teknik analisis statistik t-test. Hasil analisis, ditemukan bahwa konseling gestalt dengan teknik berkeliling dapat meningkatkan percaya diri. Disimpulkan dari hasil analisis, thitung > ttabeldengan taraf signifikansi $5 \%(4,38>2,015)$. Hasil analisis menunjukan bahwa hipotesis yang diajukan dalam penelitian ini dapat diterima. Sebagai implikasi penelitian ini diharapkan dapat menjadi alternatif bagi guru bimbingan konseling di sekolah - sekolah dalam meningkatkan percaya diri siswa.

Kata Kunci: Konseling Gestalt, Teknik Berkeliling, Percaya Diri

How to Cite: Munandar, A., Dantes, N., \& Tirka, W. (2017). Gestalt Counseling Effectiveness with Engineering Techniques to Increase Self-Consideration in Learning Process. Bisma, 1(1), 19-28. https://doi.org/10.23887/128302017 


\section{Pendahuluan}

Seperti yang tercantum dalam pendidikan Indonesia baik di sekolah maupun di luar sekolah, selalu mengarahkan pada tujuan pendidikan nasional, seperti yang tercantum dalam Undang-Undang No 20 Tahun 2003 tentang SISDIKNAS, pendidikan adalah usaha sadar dan terencana untuk mewujudkan suasana belajar dan proses pembelajaran agar peserta didik secara aktif mengembangkan potensi dirinya untuk memiliki kekuatan spiritual keagamaan, pengendalian diri, kepribadian, kecerdasan, akhlak mulia, serta keterampilan yang diperlukan diriya, masyarakat, bangsa, dan negara.

Terkait dengan pentingnya pendidikan untuk meningkatkan kualitas SDM, fungsi pendidikan nasional adalah untuk mengembangkan kemampuan dan membentuk watak, serta peradaban bangsa yang bermartabat dalam rangka mencerdaskan kehidupan bangsa ( Trianto, 2009 )("Undang-Undang Sistem Pendidikan Nasional," n.d.)(Jenderal et al., n.d.)(Anak, Sd, Belajar, \& Pendidikan, n.d.). Berdasarkan hal tersebut, hendaknya suatu pendidikan harus dikelola dengan baik dan optimal agar dapat mencapai tujuan nasional pendidikan, yaitu membentuk manusia Pancasila. Tujuan pendidikan disampaikan juga menurut Trianto ( $2009: 1$ ) yang menyatakan "Pendidikan bertujuan untuk mengembangkan potensi peserta didik agar menjadi manusia yang beriman dan bertaqwa kepada Tuhan Yang Maha Esa, berahlak mulia, sehat, berilmu, cakap, kreatif, mandiri, dan menjadi warga negara yang demokratis serta bertanggung jawab".

Perkembangan IPTEK memberikan pengaruh terhadap dunia pendidikan, dimana dengan muncul istilah e-book(elektronik book), e-learning sampai e-education. Hal ini juga berpengaruh terhadap paradigma akan "tempat" belajar tidak hanya di lingkungan sekolah namun manusia dapat belajar dimana saja dengan bantuan teknologi.

Sekolah merupakan salah satu lembaga yang memiliki kedudukan strategis dan penting dalam membentuk karakter/watak dan sikap peserta didik. Kedudukan tersebut terselenggara melalui kegiatan pembelajaran.

Belajar adalah proses yang ditandai dengan adanya perubahan pada diri seseorang. Perubahan sebagai hasil dari proses belajar dapat ditunjukkan dalam berbagai bentuk seperti berubah pengetahuan, pemahaman, sikap dan tingkah laku, keterampilan, kecakapan, kebiasaan, serta perubahan aspek-aspek lain yang ada pada individu yang belajar.

Kondisi era globalisasi seperti sekarang ini, seseorang dihadapkan pada situasi yang sangat kompleks permasalahannya, terutama remaja.

Menurut Suarni (2014: 98) (Graber \& Brooks-Gunn, 1996)(Yamaguchi \& Kandel, n.d.)(Chambers, Taylor, \& Potenza, 2003)(Clayton et al., n.d.)(Montemayor, n.d.)menyatakan,

Masa Remaja masa peralihan dari sikap tergantung (dependence) terhadap orang tua ke arah kemandirian (independence), minat-minat seksual, perenungan diri, perhatian terhadap nilai-nilai mulai dari estetika dan isu-isu moral.

Siswa SMA tergolong dalam masa remaja yang sedang mengalami proses perkembangan dan pertumbuhan. Remaja sering dihadapkan pada persoalan-persoalan yang menuntut kemampuan dalam mencapai taraf pemikiran abstrak untuk menganalisis masalah dan mencari solusi terbaik.

Siswa merupakan bagian dari makluk sosial yang hidup berdampingan dengan masyarakat di sekitarnya. Perilaku yang penting dimiliki oleh siswa adalah percaya diri, tanpa percaya diri siswa akan sulit bersosialisasi dengan teman sebayanya, tidak mampu menempatkan posisi, dan malu untuk menyampaikan pendapatnya kepada orang lain. Akibatnya siswa yang tidak memiliki percaya diri akan cenderung menutup diri, sulit berinteraksi di lingkungannya, sulit menghargai dan menerima orang lain. Percaya diri jika tidak diperhatikan maka perkembangannya dapat terhambat.

Berdasarkan hasil observasi yang dilakukan oleh peneliti saat kegiatan PLBKS yaitu pada bulan januari sampai maret 2017 di SMA Negeri 1 Singaraja. Pada saat pembelajaran di kelas XI MIA 4 terdapat siswa yang kurang maksimalmengembangkan kemampuannya. Pada saat mengerjakan tugas, siswa menunjukan sikap ketidakseriusan, siswa tidak memiliki semangat untuk belajar ketika diminta untuk menjelaskan materi di depan kelas kepada temannya, siswa tersebut tidak mau dengan alasan merasa malu. Terdapat juga Siswa yang tidak memiliki keyakinan dalam diri untuk menjawab pertanyaanpertanyaan baik dalam diskusi maupun proses pembelajaran. 
Perilaku di atas dapat mengganggu perkembangan siswa terutama dalam karir belajarnya. Hal ini disebabkan oleh kurangnya percaya diri siswa dalam mengeksplor kemampuan diri secara maksimal. Berbagai permasalahan tersebut dapat dicegah apabila siswa ataupun personalia di lingkungan sekolah tersebut memiliki percaya diri.

Berdasarkan wawancara dengan guru BK di SMA Negeri 1 Singaraja, pemberian bantuan pada siswa yang memiliki kendala dalam percaya diri, belum maksimal dilakukan. Upaya yang dilakukan oleh guru BK, didasarkan pada rasa percaya diri siswa untuk berkunjung ke ruang BK dan mengkonsultasikan permasalahannya. Selain itu, tidak adanya jam khusus mata pelajaran yang emban guru BK seperti pelajaran budi pekerti membuat guru BK tidak dapat secara intens memperhatikan keseluruhan siswa. Hal ini berdampak kurang maksimalnya kinerja guru BK dalam mengentaskan permasalahan siswa.

Percaya diri sangat diperlukan dalam proses pembelajaran di kelas karena siswa yang memiliki kendala padapercaya diri akan sulit menyampaikan apa yang diketahui atau apa yang dirasakannya baik di kelas maupun di luar kelas. Percaya diri merupakan suatu sikap atau perasaan yakin atas kemampuan sendiri.individu siswa yang memiliki percaya diri ia tidak cemas dengan tindakan yang dilakukan. Siswa dengan bebas melakukan hal yang disenangi dan siap menjalankan konsekuensi atas perbuatan yang dilakukan. Hal lain siswa memiliki interaksi yang baik dengan teman sebaya, dapat menerima dan menghargai oranglain, memiliki dorongan berprestasi serta dapat mengenal kelebihan dan kekuarangan diri.

Meningkatkan percaya diri siswa yang rendah Peneliti memilih pendekatan yang tepat untuk mengatasi permasalahan tersebut, yaitu teori konseling Gestalt.

Teori ini mampu menjelaskan cara pembentukan perilaku manusia yang dapat berubah dalam kesehariannya, dengan menggunakan beberapa langkah yang diterapkan dalam pelaksanaan konseling. Mengatasi gejala tersebut, teknik konseling yang dapat digunakan dari teori gestalt yaitu teknik berkeliling sebagai cara meningkatkan percaya diri siswa.

Teknikberkeliling merupakan bagian dari teknik konseling gestalt. Penerapannya konselor meminta klien untuk mampu menghadapi, memberanikan dan menyingkapkan diri, bereksperimen dengan tingkah laku yang belum pernah ia lakukan serta tumbuh dan berubah melalui beberapa prosedur treatmen.

Jadi dengan menerapkan konseling gestalt melalui teknik berkeliling, siswa yang memiliki percaya diri rendah dapat mencoba berbicara dan melakukan aktivitas baru melalui beberapa prosedur untuk meningkatkan percaya diri.

Berdasarkan latar belakang di atas, maka dapat dilakukan penelitian yang berjudul "Efektifitas Konseling Gestalt dengan Teknik Berkeliling untuk meningkatkan percaya diri dalam proses pembelajaran pada siswa kelas XI MIA 4 SMA Negeri 1 Singaraja Tahun 2016/2017 ”

\section{Metode}

Penelitian ini termasuk penelitian pra eksperimen. Rancangan penelitian menggunakan "One Group Pretest-Posttest Design". Perlakuan dalam design ini diberikan terhadap suatu kelompok, kemudian dilakukan pengambilan data. Sebelum perlakuan diberikan, dilakukan pratest.Adapun tujuan daripenelitian ini adalah untuk mengetahui Efektifitas Konseling Gestalt dengan Teknik Berkeliling dalam Meningkatkan Percaya diri siswa dalam proses pembelajaran.

Dalam penelitian ini yang dimaksud populasi penelitian adalah siswa kelas XI MIA 4 SMA Negeri 2 Singaraja yang berjumlah 30 orang siswa Tahun Ajaran 2016/2017. Adapun metode sampling yang dipakai pada penelitian ini adalah teknik purposive sampling. Menurut Dantes, (2012:46-47) menyatakan bahwa "Purposive sampling merupakan teknik penarikan sampel yang didasarkan pada ciri atau karakteristik (tujuan) yang ditetapkan oleh peneliti sebelumnya maka yang dimaksud sampel dalam penelitian ini adalah siswa yang dapat mewakili keseluruhan populasi yang menunjukkan gejala percaya diri rendah.

Variabel bebas dalam penelitian ini adalah konseling gestalt dengan teknik berkeliling. Variabel terikat dalam penelitian ini percaya diri. Data dalam penelitian ini merupakan skor percaya diri siswa yang 
diperoleh melalui hasil kuesioner pola likert dimana sebelum diujicobakan, tes diuji validitas dan reabilitasnya.

Penelitian ini menggunakan kuisioner sebagai alat untuk mengumpulkan data. Menurut Margono (2005:167) menyatakan bahwa kuesioner suatu alat pengumpul informasi dengan cara menyampaikan sejumlah pertanyaan tertulis untuk menjawab secara tertulis pula oleh responden. Kuesioner ini digunakan untuk mengetahui percaya diri siswa. Data yang dikumpulkan dalam penelitian ini adalah data tentang percaya diri yang sebenar-benarnya hanya diketahui oleh responden sendiri. Untuk memperoleh data tersebut, digunakan instrumen kuesioner percaya diri yang dikembangkan berdasar teori yang relevan.

Untuk mengukur variabel percaya diri maka disusun pernyataan-pernyataan kuesioner percaya diri. Kuesioner mengacu pada pola likert dengan lima rentangan jawaban secara bertingkat, yaitu: sangat sesuai (SS), sesuai (S), kurang sesuai (KS), tidak sesuai (TS) dan sangat tidak sesuai (STS). Dimana skor bergerak dari skor satu sampai lima. Dalam pertanyaan positif, responden menjawab sangat sesuai (SS) diberi skor 5, sesuai (S) diberi skor 4, kurang sesuai (KS) diberi skor 3, tidak sesuai (TS) diberi skor 2, sangat tidak sesuai (STS) diberi skor 1. Bila pertanyaan negatif, maka penskoran sebaliknya.

Pada tanggal 03 Juni 2017 dimulai dengan pelaksanaan tes awal (Pratest) yang dilakukan di Kelas XI MIA 4. Penyebaran kuesioner dilaksanakan sebelum pelaksanaan treatment. Data yang diperoleh dari tes awal ini merupakan data awal penelitian. Pelaksanaan penelitian pada tanggal 05 Juni 2017 dengan pelaksanaan konseling gestalt dengan teknik berkeliling untuk meningkatkan percaya diri siswa. Treatment dilakukan sebanyak 8 kali pertemuan dengan 7 kali treatmentdan 1 kali posttest. Treatmentdijabarkan dalam bentuk RPBK yang berjumlah 7 buah disesuaikan jumlah pertemuan yang direncanakan.

Pada pertemuan 1) Perkenalan dan membuat komitmen, Siswa dapat mengetahui tujuan dari kegiatan yang akan dilaksanakan mampu memegang teguh komitment dalam melaksanakan konseling kelompok untuk meningkatkan percaya diri, memberikan penjelasan tentang percaya diri dan aspek-aspek individu yang memiliki percaya diri tinggi2) menumbuhkan semangat untuk memberanikan dri berbicara di depan anggota kelompok. Konseli dapat memahami kelemahan dan kelebihan yang dimiliki serta mampu mencari solusi dari kelemahan yang dimiki dalam memahami diri sendiri dalam setting teknik berkeliling 3) mampu mencoba sesuatu yang baru dalam bentuk perilaku dan juga kemampuan berbicara di depan anggota kelompok,Agar konseli terbiasa dalam menyampaikan pendapat kepada orang lain dalam setting teknik berkeliling, 4) Mampu menjaga kestabilan emosi seperti bersikap tenang dalam menyampaikan pendapat, menghilangkan perasaan takut serta kekhawatiran yang mengganggu pikiran dalam setting teknik berkeliling, 5) memberikan kesempatan kepada konseli untuk menyampaikan pendapat di depan kelompok dengan tema pembahasan yang telah ditentukandalam setting teknik berkeliling 6) mengajak konseli mampu berinteraksi dengan orang lain melalui permainan menyampaikan pendapat dalam setting teknik berkeliling 7) Menegaskan kembali kepada konseli agar mampu meningkatkan percaya diri melalui tahap-tahap yang sudah dilakukan pada pertemuan sebelumnya, 8) Evaluasi dari hasil konseling yang sudah dilaksanakan. Selanjutnya pada tahap akhir penelitian sampel penelitian diberikan kuesioner percaya diri untuk mengetahui sejauh mana konseling gestalt dengan teknik berkeliling efektif dalam meningkatkan percaya diri siswa. Dalam penelitian ini data dianalisis dengan statistic menggunakan uji ttest.

\section{Hasil dan Pembahasan}

Adapun rekapitulasi data percaya diri pretest dan posttest pada kelompok eksperimen.

Tabel 4.1.

Rekapitulasi Data Score pretest dan posttest kelompok Eksperiment

\begin{tabular}{ccccc}
\hline No & Pretest & Posttest & Gain Skor & Gain Skor Normality \\
& & & & \\
\hline $\mathbf{1}$ & 77 & 153 & 76 & 0,62 \\
$\mathbf{2}$ & 73 & 144 & 71 & 0,56 \\
\hline
\end{tabular}




\begin{tabular}{ccccc}
\hline $\mathbf{3}$ & 90 & 145 & 55 & 0,50 \\
$\mathbf{4}$ & 82 & 150 & 68 & 0,58 \\
$\mathbf{5}$ & 78 & 144 & 66 & 0,54 \\
$\mathbf{6}$ & 68 & 176 & 108 & 0,82 \\
Total & 468 & 912 & 444 & 3,61 \\
Rata - rata & 78 & 152,00 & 74,00 & 0,60 \\
\hline
\end{tabular}

Pada tabel 4.1 hasil analisis pretest6 siswa yang memilki percaya diri rendah menunjukkan adanya peningkatan skor dari pretestke posttest.

Tabel 4.2

Kriteria Penetapan Kualifikasi Skor Percaya diri

\begin{tabular}{cc}
\hline Rentang Skor & Kualifikasi \\
\hline $\mathbf{1 8 0} \leq \mathbf{2 0 0}$ & Sangat Tinggi \\
$\mathbf{1 5 0} \leq \mathbf{1 8 0}$ & Tinggi \\
$\mathbf{1 2 0} \leq \mathbf{1 5 0}$ & Sedang \\
$\mathbf{8 0} \leq \mathbf{1 2 0}$ & Rendah \\
$\mathbf{4 0} \leq \mathbf{8 0}$ & Sangat Rendah \\
\hline
\end{tabular}

Tabel skor digunakan untuk melihat kualifikasi hasil yang didapatkan dari setiap siswa yang dijadikan sampel penelitian. pada tabel 4.1 tampak data hasil pretest, posttest pada kelompok eksperiment control, dapat dilihat bahwa skor pencapaian pretest pada kelompok eksperimen setelah dilakukan posttest pada kelompok eksperiment sudah naik menjadi kualifikasi tinggi. Dari hasil tersebut sudah menunjukkan bahwa adanya peningkatan padakelompok eksperimen.

Berdasarkan data dalam tabel 4.1 Nampak adanya peningkatan percaya diri setelah diberikan posttest pada kelompok eksperiment dan kontrol, yang dijabarkan dalam gambar 4.1 dan gambar 4.2

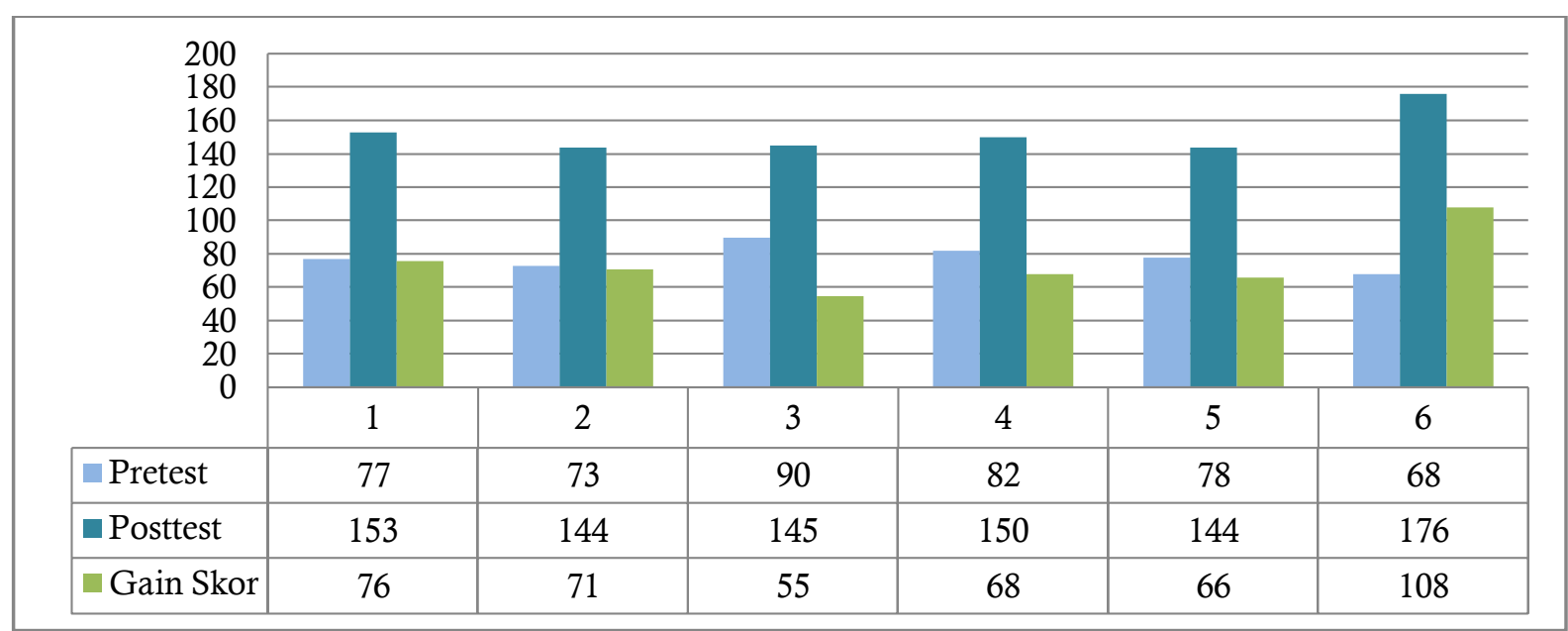

Gambar.4.1 Grafik Skor Pretest, Posttest dan Gain SkorPercaya diri 
Hasil di atas dapat diketahui bahwa terjadi peningkatan skor yang tinggi pada data posttest, hal ini berarti konseling gestalt dengan teknik berkeliling efektif meningkatkan percaya diri dalam proses pembelajaran.

Rumusan hipotesis pada penelitian ini yaitu konseling gestalt dengan teknik berkeliling efektif meningkatkan percaya diri dalam proses pembelajaran pada siswa kelas XI MIA 4 SMA Negeri 1 Singaraja tahun ajaran 2016/2017.

Untuk mengetahui pengaruh dari variabel bebas terhadap variabel terikat dapat dilihat dari perbedaan pretest dengan posttest. Secara statistik dengan ststistik t-test yang lebih dikenal dengan uji t-test dimaksudkan untuk mengetahui pengaruh variabel bebas terhadap variabel terikat dilihat dari perbedaan pretest dan posttest. Untuk memudah perhitungan, dibantu dengan Program Microsoft office excel 2007.

Tabel 4.5 Hasil Analisis t-brunning

\begin{tabular}{|c|c|c|c|}
\hline No & Nama & $\mathbf{X}$ & $\mathrm{X}^{2}$ \\
\hline 1 & MST & 153 & 23409 \\
\hline 2 & SM & 144 & 20736 \\
\hline 3 & $\mathrm{BC}$ & 145 & 21025 \\
\hline 4 & PAA & 150 & 22500 \\
\hline 5 & $\mathrm{AP}$ & 144 & 20736 \\
\hline \multirow[t]{3}{*}{6} & KSC & 176 & 30976 \\
\hline & $\Sigma$ & 912 & 139382 \\
\hline & Mean & 155,17 & 24080,83 \\
\hline
\end{tabular}

Sesuai dengan judul penelitian dan teori yang ada, maka hipotesis statistik yang digunakan untuk menganalisis data adalah sebagai berikut.

$\mathrm{H} 0=$ Konseling Gestalt dengan teknik berkeliling efektif untuk meningkatkan percaya diri dalam proses pembelajaran pada siswa kelas XI MIA 4 SMA Negeri 1Singaraja.

Berdasarkan hasil uji hipotesis pada tabel diatas didapatkan nilai thitung $=4,38$ dengan $\mathrm{df}=(\mathrm{n}-1)=(6-$ 1) $=5$ dengan taraf signifikansi $5 \%$ maka diperoleh nilai ttabel $=2,015$. Berdasarkan hasil tersebut dapat disimpulkan bahwa nilai thitung $>$ ttabel atau 4,38>2,015. Dengan demikian maka dapat disimpulkan bahwa Ha yang menyatakan "Konseling gestalt dengan teknik berkeliling efektif meningkatkan percaya diri dalam proses pembelajaran pada siswa kelas XI MIA 4 SMA Negeri 1 Singaraja tahun ajaran 2016/2017" diterima.diterima. Selanjutnya dikonfigurasikan intensitas (katagori) efektifitasnya (effect size).

Besarnya nilai ES $=1,80$ maka ES berada pada kategori tinggi, sehingga dapat dinyatakan bahwa konseling gestalt dengan teknik berkeliling efektifitasnya tinggi dalam meningkatkan percaya diri dalam proses pembelajaran pada siswa kelas XI MIA 4 SMA Negeri 1 Singaraja tahun ajaran 2016/2017. 
Pembahasan hasil penelitian yang dipaparkan pada bagian ini adalah hasil-hasil analisis deskriptif terkait konseling gestalt dengan teknik berkeliling efektif meningkatkan percaya diri dalam proses pembelajaran pada siswa kelas XI MIA 4 SMA Negeri 1 Singaraja tahun ajaran 2016/2017.

Corey (2003: 118)(Desolneux, Moisan, \& Morel, n.d.)(Chang, Dooley, \& Tuovinen, n.d.) mengatakan bahwa asumsi dasar teori gestalt adalah bahwa individu-individu mampu menangani masalah-masalahnya sendiri secara efektif dan menerima tanggung jawab pribadi jika mereka berharap mencapai kematangan. Dengan demikian seorang konselor memiliki peran untuk membantu siswa untuk dapat mengalami sepenuhnya keberadaannya "disini" dan "sekarang" dengan menyadarkannya atas tindakan mencegah diri sendiri, merasakan dan mengalami sekarang.

Teknik yang digunakan dalam penelitian ini untuk memberikan perlakuan terhadap percaya diri, yaitu teknik berkeliling merupakan teknik konseling yang membantu siswa dalam mencapai perkembangan yang matang dan lebih sadar akan apa yang terjadi dalam dirinya melalui meminta klien berkeliling ke anggota kelompoknya, berbicara atau melakukan aktivitas dengan anggota itu(Hertiavi, Langlang, Khanafiyah, Negeri, \& Jurusan Fisika, n.d.; Karacop \& Doymus, n.d.; Mattingly \& Vansickle, n.d.; Murphy, Blaha, Vandegrift, Wolfman, \& Zander, n.d.)Teknik berkeliling digunakan untuk mengidentifikasi, memperbaiki perilaku yang tidak dimiliki atau ingin memperbaiki perilaku seseorang dengan mencoba berkeliling pada kelompok yang telah ditentukan dan melakukan aktivitas berupa percakapan atau perilaku baru.

Pendekatan konseling dan teknik diatas digunakan dalam proses konseling bersama siswa yang dikategorikan memiliki percaya dirirendah, kelompok dibentuk dan pelaksanaan konseling dilakukan untuk mengetahui efektifitas yang terjadi kepada individu yang memiliki percaya diri rendah. Percaya diri sangat penting dalam diri individu karena dengan percaya diri yang tinggi individu dapat bertahan dalam kesulitan dan dapat menghadapi masalah yang dialami, namun tidak jarang individu kurang paham mengenai percaya diri itu sendiri, karena hal tersebut dilaksanakan konseling gestalt dengan teknik berkeliling.

Proses konseling bertujuan untuk membantu siswa dalam mencapai perkembangan yang matang dan lebih sadar akan apa yang terjadi pada dirinya serta mampu menghadapi situasi yang sulit. Seseorang yang memiliki percaya diri yang tinggi mampu bertahan dalam kesulitan dan menghadapi tantangan dengan kemampuan dan keterampilan yang dimiliki.

Temuan empiris ada penelitian ini menyatakan bahwa didapatkan nilai thitung $=4,38$ dengan $\mathrm{df}=(\mathrm{n}$ $1)=(6-1)=5$ dengan taraf signifikansi $5 \%$ maka diperoleh nilai ttabel $=2,015$. Berdasarkan hasil tersebut dapat disimpulkan bahwa nilai thitung $>$ ttabel atau 4,38>2,015. Dengan demikian maka dapat disimpulkan bahwa $\mathrm{Ha}$ yang menyatakan "Konseling gestalt dengan teknik berkeliling efektif meningkatkan percaya diri siswa dalam proses pembelajaran pada siswa kelas XI MIA 4 SMA Negeri 1 Singaraja Tahun 2016/2017" diterima.

Selanjutnya dikonfigurasikan intensitas (katagori) efektifitasnya (effect size) didapatkan besarnya nilai ES $=1,8$ maka ES berada pada kategori tinggi, setelah dikonfigirasi sesuai kriteria dapat dinyatakan bahwa konseling gestalt dengan teknik berkeliling efektifitasnya tinggi untuk meningkatkan percaya diri siswa.

Hasil yang didapatkan di atas memberikan dampak positif setelah pelaksanaan konseling, dapat disimpulkan bahwa memang konseling gestalt dengan teknik berkelilingefektifitasnya tinggi untuk meningkatkan percaya diri siswa.

Dengan demikian, hipotesis penelitian berbunyi "Konseling Gestalt dengan teknik berkeliling efektif untuk meningkatkan percaya diri dalam proses pembelajaran pada siswa kelas XI MIA 4 SMA Negeri 1 Singaraja tahun ajaran 2016/2017" telah teruji.

\section{Kesimpulan}

Berdasarkan hasil dan pembahasan, dapat disimpulkan sebagai berikut. Konseling gestalt dengan teknik berkeliling efektif untuk meningkatkan percaya diri dalam proses pembelajaran pada siswa kelas XI MIA 4 SMA Negeri 1 Singaraja tahun ajaran 2016/2017. 


\section{Referensi}

Antari, Ni Nengah Madri. (2014). Buku Ajar Belajar dan Pembelajaran. Jurusan Bimbingan konseling, Fakultas Ilmu Pendidikan: UNDIKSHA Singaraja.

Arikunto, S. (2005). Manajemen Penelitian. Jakarta: Rineka Cipta.

Arif, Antonius. (20140. Resource Therapy, Ego State Therapy of Gordon Emmerson. Jakarta: Spasi Media.

Anak, P., Sd, D., Belajar, K., \& Pendidikan, D. (n.d.). Hakikat Pendidikan di Sekolah Dasar.

Chambers, R. A., Taylor, J. R., \& Potenza, M. N. (2003). Developmental Neurocircuitry of Motivation in Adolescence: A Critical Period of Addiction Vulnerability. American Journal of Psychiatry, 160(6), 1041-1052. https://doi.org/10.1176/appi.ajp.160.6.1041

Chang, D., Dooley, L., \& Tuovinen, J. E. (n.d.). Gestalt Theory in Visual Screen Design - A New Look at an Old Subject.

Clayton, P. E., Cuneo, R. C., Juul, A., Monson, J. P., Shalet, S. M., \& Tauber, M. (n.d.). Consensus statement on the management of the GH-treated adolescent in the transition to adult care. European Journal of Endocrinology, 152, 165-170. https://doi.org/10.1530/eje.1.01829

Corey, Gerald. (2003a). Teori dan Praktek Konseling dan Psikoterapi. Bandung: PT Refika ADITAMA

Corey, Gerald. (2013b). Teori dan Praktek Konseling dan Psikoterapi. Bandung: PT Refika ADITAMA

Dantes, Nyoman. (2014a). Analisis dan Desain Eksperimen. Singaraja: Program Pascasarjana Undiksha.

Dantes, Nyoman. (2012b). Metode Penelitian. Yogyakarta: Andi Offset.

Desolneux, A., Moisan, L., \& Morel, J.-M. (n.d.). From Gestalt Theory to Image Analysis.

Djiwandono, Sri Esti Wurdani. (2005). Konseling dan Terapi dengan Anak dan Orangtua. Jakarta: PT Grasindo.

Graber, J. A., \& Brooks-Gunn, J. (1996). Transitions and Turning Points: Navigating the Passage From Childhood Through Adolescence. Developmental Psychology, 32(4), 768-776.

Gunarsa, Singgih D. (2004). Konseling dan Psikoterapi. Jakarta: PT BPK Gunung Mulia

Hartono dan Soedarmadji. (2012). Psikologi Konseling : Edisi Revisi. Jakarta: Kencana.

Hertiavi, M. A., Langlang, H., Khanafiyah, S., Negeri, S., \& Jurusan Fisika, K. (n.d.). Penerapan Model Pembelajaran Kooperatif Tipe Jigsaw Untuk Peningkatan Kemampuan Pemecahan Masalah Siswa SMP.

Jenderal, D., Non, P., Dan, F., Direktorat, I., Kursus, P., Kelembagaan 2009, D., ... Rasional, A. (n.d.). MUSIK KEMENTERIAN PENDIDIKAN NASIONAL.

Kartono, Kartini. (1997). Patologi Sosial. Jakarta: CV. Rajawali.

Karacop, A., \& Doymus, K. (n.d.). Effects of Jigsaw Cooperative Learning and Animation Techniques on Students' Understanding of Chemical Bonding and Their Conceptions of the Particulate Nature of Matter. https://doi.org/10.1007/s10956-012-9385-9

Komalasari, Gantina., dkk. (2011). Teori dan Teknik Konseling. Jakarta: PT. Indeks. 
Lubis, Namora Lumongga. (2011). Memahami Dasar-Dasar Konseling dalam Teori dan Praktik. Jakarta: Kencana.

Mattingly, R. M., \& Vansickle, R. L. (n.d.). Cooperative Learning And Achievement In Social Studies: Jigsaw Ii Cooperative Learning And Achievement In.

Montemayor, R. (n.d.). Parents and Adolescents in Conflict: All Families Some of the Time and Some Families All of the Time.

Murphy, L., Blaha, K., Vandegrift, T., Wolfman, S., \& Zander, C. (n.d.). Active And Cooperative Learning Techniques For The Computer Science Classroom.

Malahayati. (2010). SUPER TEENS, Jadi Remaja Luar Biasa dengan Kebiasaan Efektif. Yogjakarta: Percatakan Galangpress

Mappiare AT, Andi. (2004). Pengantar Konseling dan Psikoterapi. Jakarta Utara: PT Raja Grafindo Persada

Mulyasa, E. (2009). Implementasi KTSP Kemandirian Guru dan Kepala Sekolah. Jakarta: Bumi Aksara.

Margono. (2005). Metodologi Penelitian Pendidikan. Jakarta: PT Rineka Cipta.

Nurkancana, Wayan Sunartana. (1990). Evaluasi Hasil Belajar. Surabaya: Usaha National.

Prayitno dan Erman Amti. (2004a). Dasar-Dasar Bimbingan dan Konseling. Jakarta: Direktorat Jenderal Pendidikan Tinggi.

Prayitno dan Erman Amti. (2004b). Dasar-Dasar Bimbingan dan Konseling. Jakarta: PT Rineka Cipta.

Sedanayasa, Gede dan Kadek Suranata. (2009). Buku Ajar: Dasar-Dasar Bimbingan Konseling. Singaraja: Jurusan Bimbingan Konseling, Fakultas Ilmu Pendidikan: Universitas Pendidikan Ganesha.

Subini, Nini. (2014). YOU CAN DO IT, Ragam Ide Jitu Penangkal Rasa Grogi. Jakarta Selatan: Flash Books

Sugiono. (2009). Metode penelitian Kualitatif Kuantitatif dan R\&D. Bandung: ALFABETA

Suarni, Ketut. (2014). Modul perkembangan Individu. Singaraja: UNDIKSHA

Sukardi, Dewa Ketut. (2002a). Pengantar Pelaksanaan Program Bimbingan dan Konseling di Sekolah. Jakarta: PT. Rineka Cipta.

Sukardi. (2003b). Metodologi Penelitian Pendidikan. Jakarta: PT Bumi Aksara.

Undang-Undang Sistem Pendidikan Nasional. (n.d.).

Widjaja, Hendra. (2016). Berani Tampil Beda dan Percaya Diri. Yogyakarta: Araska

Yeo, Anthony. (2003), Konseling Suatu Pendekatan Pemecahan Masalah, Jakarta: PT BPK Gunung Mulia.

Yamaguchi, K., \& Kandel, D. B. (n.d.). Patterns of Drug Use from Adolescence to Young Adulthood: II. Sequences of Progression. 
Conflict of Interest Disclosures:

The authors declare that they have no significant competing financial, professional or personal interests that might have influenced the performance or presentation of the work described in this manuscript.

Copyrights Holder: Arief Munandar, Nyoman Dantes, Wayan Tirka 2017

First Publication Right: BISMA The Journal of Counseling

https://doi.org/10.23887/128302017

Open Access Article | CC-BY Creative Commons Attribution 4.0 International License.

Word Count: 